\title{
Closed-System Oxygen Isotope Exchange in a Paleoproterozoic Evaporite Sequence
}

\author{
HaOran MA ${ }^{1,3}$, Yongbo PenG ${ }^{2,3}$, Riho MõTleP ${ }^{4}$, \\ KALLE KIRSIMÄE ${ }^{4}$, ALEKSANDER ROMASHKIN ${ }^{5}$, AIVO \\ LEPLAND $^{4,6}$, HUIMING BAO ${ }^{2,3}$ \\ ${ }^{1}$ School of Earth and Space Sciences, Peking University, \\ Beijing, 100871, China \\ ${ }^{2}$ School of Earth Sciences and Engineering, Nanjing \\ University, Nanjing 210023, China. \\ ${ }^{3}$ Department of Geology and Geophysics, Louisiana State \\ University, Baton Rouge, LA 70803, USA \\ ${ }^{4}$ Tartu University, 50411 Tartu, Estonia \\ ${ }^{5}$ Karelian Research Centre, 185610 Petrozavodsk, Russia \\ ${ }^{6}$ Geological Survey of Norway, 7491 Trondheim, Norway
}

Post-depositional processes including diagenesis and metamorphism could alter the $\delta^{18} \mathrm{O}$ and obscure the original signal. We have studied the oxygen isotope composition of the Earth's oldest major evaporite succession from the Onega Basin, Russian Karelia and found an upward increasing $\delta^{18} \mathrm{O}$ trend in three co-occurring phases; carbonates (from $13 \%$ to $22 \%$, VSMOW), sulfates (from $11 \%$ to $19 \%$ ), and silicates (from $10 \%$ to $21 \%$ ). After discounting the possibility of a high initial temperature gradient in the basin or a freshwaterto-open seawater transition, we propose that the linked upward increase in the $\delta^{18} \mathrm{O}$ for carbonates, sulfates, and silicates is the result of an upward decrease in initial gypsum proportion in the chemical sediments. Low-grade metamorphic minerals talc, phlogopite, chlorite, and tourmaline indicate that crystallization fluids reacted with these chemical sediments at $200 \sim 300{ }^{\circ} \mathrm{C}$, then oxygen exchange occurred between minerals and water. Massbalance calculation based on elemental and mineralogy data is consistent with proposed closed-system re-equilibration causing the upward $\delta^{18} \mathrm{O}$ shift of all three phases. These calculations further infer that the $\delta^{18} \mathrm{O}$ of Paleoproterozoic seawater was at $-1 \sim-2 \%$. 